\title{
CONWIP versus POLCA: A Comparative Analysis in a High-Mix, Low-Volume (HMLV) Manufacturing Environment with Batch Processing
}

\author{
Todd Frazee $^{1}$ (D), Charles Standridge ${ }^{2}$ iD \\ ${ }^{1}$ Electro-Optics Technology, Inc, Traverse City, Michigan (United States) \\ ${ }^{2}$ Grand Valley State University (United States) \\ toddandamber@gmail.com,standric@gvsu.edu
}

Received: September 2014

Accepted: April 2016

\section{Abstract:}

Purpose: Few studies comparing manufacturing control systems as they relate to high-mix, lowvolume applications (HMLV) have been reported. This paper compares two strategies, constant work in process (CONWIP) and Paired-cell Overlapping Loops of Cards with Authorization (POLCA), for controlling work in process (WIP) in such a manufacturing environment. Characteristics of each control method are explained in regards to lead time, maximum work in process, and throughput and thus, why one may be advantageous over the other.

Design/methodology/approach: An industrial system in the Photonics industry is studied. Discrete event simulation is used as the primary tool to compare performance of CONWIP and POLCA controls. Model verification and validation are accomplished by comparing historic data to simulation generated data including utilizations. Simulation experimentation includes a constant case in which all quantities in the model are constant and a random case where the number of orders, pieces per order, and operation times are random variables. These two cases represent the best and practical worst case performance of the system, respectively.

Findings: For the system considered in this case study, which includes batch processing, a CONWIP control maximizes throughput at a lower maximum WIP level than a POLCA control. Lead times are equivalent. The performance of POLCA and CONWIP with respect to lead time 
and throughput becomes equivalent for higher levels of WIP. This is true for both the constant and random cases.

Practical implications: The POLCA control strategy uses multiply parameters that in effect specify the maximum WIP in specific areas of the system whereas the CONWIP control is simpler, using a single parameter to specify the upper bound on the overall WIP in the system. In other words, POLCA can potentially prevent all the allowed WIP from congregating in one area of the system and thus preventing relatively large lead times whereas CONWIP does not. In this case, the more detailed control provided by the POLCA system was shown to be unnecessary as the simpler CONWIP control was sufficient. This appears to be due to the batch processing operations and the relatively low utilization of many of the operations.

Originality/value: The study compliments and extends previous studies comparing CONWIP and POLCA performance to a HMLV manufacturing environment with batch operations. It demonstrates the utility of discrete event simulation. It shows how to evaluate trade-offs between the single parameter CONWIP control strategy and the multi-parameter POLCA control strategy with regard to maximum WIP, throughput, and lead time.

Keywords: CONWIP, POLCA, HMLV manufacturing, simulation

\section{Introduction}

Two strategies for controlling work in process (WIP) are Constant Work in Process (CONWIP) and Paired-cell Overlapping Loops of Cards with Authorization (POLCA). It is important to determine the conditions under which each is best used. Doing so is illustrated through a case study involving an industrial system from the Photonics industry which operates as a cellular production environment. Lead time, maximum WIP, and throughput are the primary metrics for comparison. This study compliments and extends previous comparisons of POLCA and CONWIP, through an application in a high-mix, low-volume (HMLV) environment with batch operations.

There have been few reported previous efforts to compare POLCA and CONWIP. Godinho-Filho and Saes (2013) provide a thorough review of lead time reduction research, which does not identify any such comparisons. Sakhardande (2011) reports a simulation based study similar to this one comparing KANBAN and CONWIP controls. 
The few reported studies generally have been confined to only single product systems (Krishnamurthy \& Suri, 2000). Some even suggest that direct relation between pull signal and product type is not that useful in HMLV environments because the greater product variety leads to a very large number of different bins or cards as WIP releases limit the quantity of products between processes. In addition, the repetition of identical orders is not that frequent, which could lead to long waiting times of intermediate stock in queue bins (Germs \& Riezebos, 2010).

In a CONWIP control, the production process in a high-mix environment is viewed as only one large single loop. Jobs that travel similar but different routings using different equipment can have unnecessary idle time at some stations, while long queue times at others (Suri, 2010). However, CONWIP offers flexibility by not requiring a common or shared process flow by all products in the loop.

It is suggested that POLCA can have advantages over a KANBAN control system in a high demand variability [high-mix] environment (Kabadurmus, 2009). This tends to lend itself toward the HMLV manufacturing model where orders can be of varying size in varying frequency. Furthermore, Suri (2010) suggests that machines and process groupings can make the system less complicated and easier to implement.

One primary study comparing CONWIP and POLCA is by Germs and Riezebos (2010) who studied pull systems in make-to-order (MTO) production. They state that improvements in average total throughput time are due to the workload balancing capability of a pull system, but that many systems lack this capability. They conclude that the workload balancing capability exists for POLCA but that the magnitude of the effect significantly differs, depending on the operating parameter values, utilization level, order arrival patterns and processing times of the orders. However, Germs and Riezebos (2010) suggest that a POLCA system could face longer shop floor lead times when compared to a similar CONWIP system. Kabadurmus (2009) had similar results when comparing POLCA and CONWIP in a hypothetical system.

\section{Control Systems}

WIP control systems allow the maximum amount of WIP to be specified. CONWIP and POLCA are two such control approaches.

\subsection{CONWIP}

The single parameter in a CONWIP system is the overall limit it places on the WIP inventory level. WIP may congregate at different points at different times depending on the order sequencing. Within the 
CONWIP loop, the quantity of WIP, jobs being processed plus waiting to be processed, is kept constant. As a job leaves the loop, it triggers a new job to enter the loop as shown in Figure 1.

By limiting the volume/quantity of jobs in the loop, inventory levels are controlled and machines or work cells have a more constant flow of work, thus limiting lead time. Some claim that this is the simplest form of a pull system (Spearman, Woodruff \& Hopp, 1990).

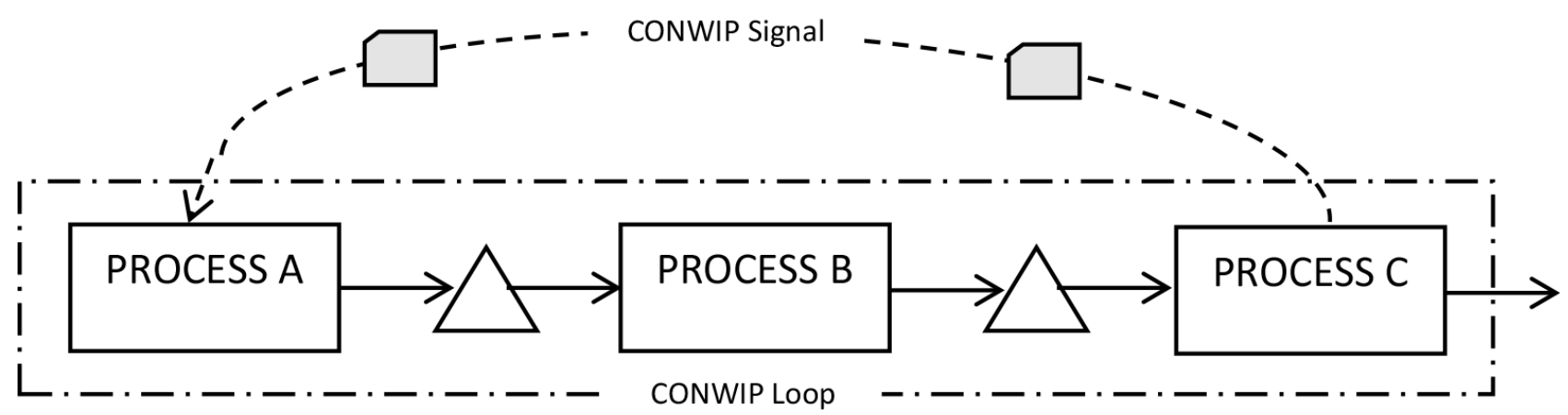

Figure 1. Simple CONWIP system

\subsection{POLCA}

Job movement between any two cells/process in a POLCA system is controled by POLCA cards specific to that loop. The number of cards is the key parameter which limits the WIP inventory. For this reason they are often referred to as capacity signals rather than inventory signals.

A simple three-loop POLCA system is shown in Figure 2. Each loop contains a specific number of cards that are specific to only that loop. Cards are labeled with an origin and destination cell/process. In order for a job to begin work at any particular cell/process it must have a POLCA card. Once finished processing at the "origin" cell/process, the job and card are passed to the "destination" cell/process. Once finished processing at the destination cell/process the card goes back to the origin cell/process, while the job can only move forward if it has an available POLCA card to accompany it to the next cell/process. For this reason, the POLCA signal controls capacity and the number of cards sets an upper limit on the amount of WIP in the system. Suri (2010) states that POLCA control systems have been best used in MTO systems that have higher customization/mix and lower volumes: HMLV. 


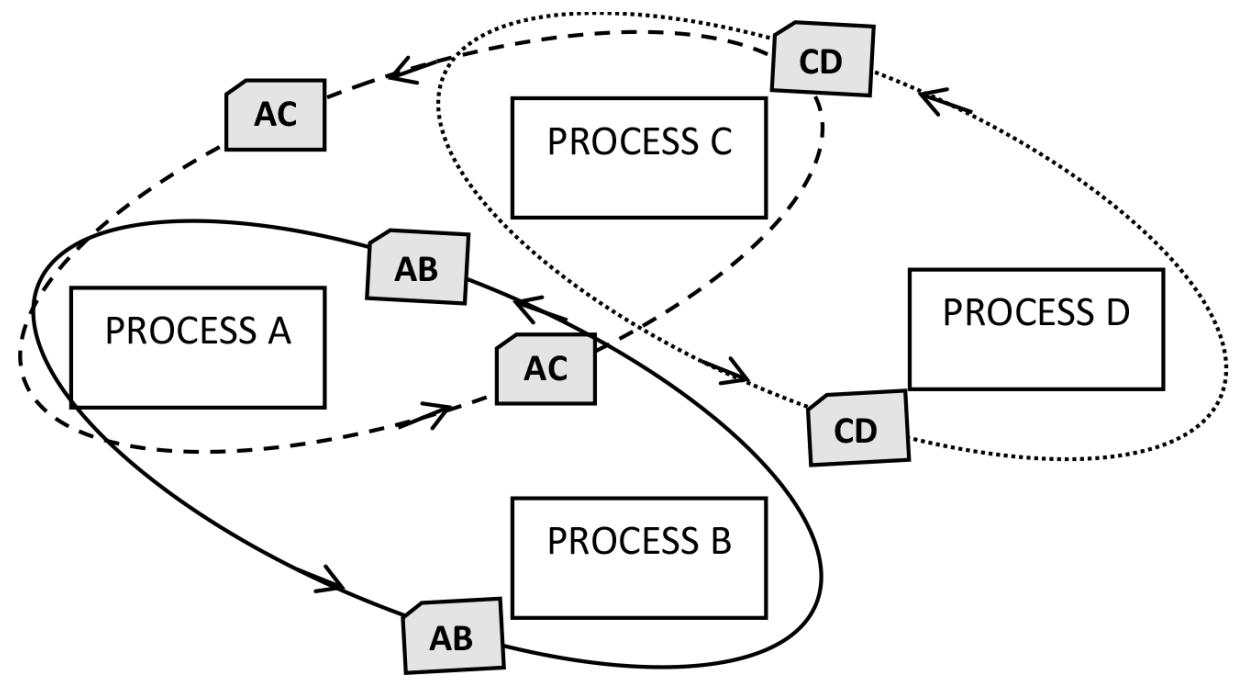

Figure 2. Simple Three Loop POLCA system

\section{High Mix Low Volume Systems (HMLV)}

One manufacturing classification, HMLV, refers to production of a variety of products with small order quantity and frequency (the volume), and a high number of differing products (the mix) as shown in Figure 3. This is typical of MTO and/or engineered-to-order (ETO) systems.

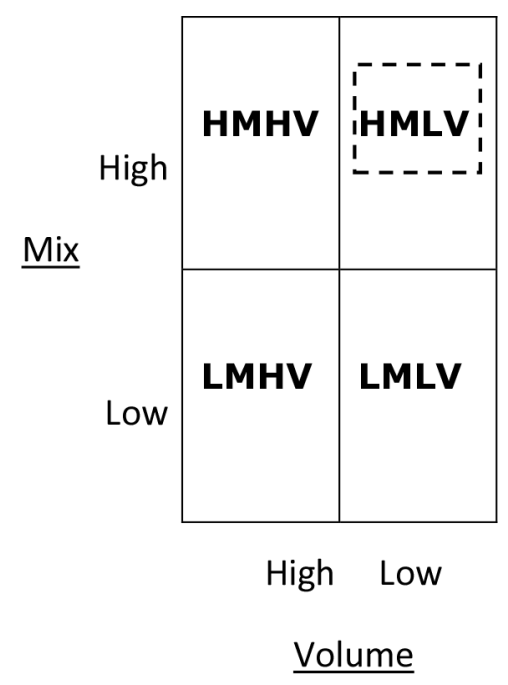

Figure 3. Manufacturing Type Matrix

Control and management of HMLV can be difficult as a result of distinct job routings, varying process times, specific due dates and limited resources shared across different routings (Suri, 2010). Assembly Magazine reports that as model mix increases and production volume decreases, assemblers are discovering that lean, CONWIP, and KANBAN manufacturing strategies no longer apply (Sprovieri, 
2004). The volatility results in manufacturers needing to supply many different parts types to many different customers, rather than a large volume one part to one customer (Duggan, 2002). As a result, high-mix manufacturers earn business based primarily on how quickly, minimal lead time, they can deliver exactly what their customers want.

Photonics is such an industry. Historically, this industry could be classified as mostly research and development with small prototype orders. Continuing technology evolution has led to more products that include lasers leading to expanding customer bases demanding more product variations.

\section{The Case Study Manufacturing System}

The HMLV system consisted of twelve distinct processes. Two similar products with varying sizes, optical isolators and rotators, will be routed through the system by a process flow that is product and/or customer order predetermined as shown in Table 1.

\begin{tabular}{|c|c|c|c|c|c|c|c|c|c|c|c|c|c|}
\hline Product & $\begin{array}{l}\text { Variation } \\
\text { (Flow) }\end{array}$ & Mach & Coat & Etch & $\begin{array}{c}\text { Clean } \\
1\end{array}$ & $\begin{array}{c}\text { Assy } \\
1\end{array}$ & $\begin{array}{c}\text { Assy } \\
2\end{array}$ & $\begin{array}{c}\text { Cure } \\
1\end{array}$ & $\begin{array}{c}\text { Cure } \\
2\end{array}$ & $\begin{array}{c}\text { Assy } \\
3\end{array}$ & $\begin{array}{c}\text { Assy } \\
4\end{array}$ & Align & Test \\
\hline \multirow{4}{*}{ Rotator } & A & $\mathrm{X}$ & $\mathrm{X}$ & $\mathrm{X}$ & $\mathrm{X}$ & $X$ & & $\mathrm{X}$ & & $\mathrm{X}$ & $\mathrm{X}$ & $\mathrm{X}$ & $\mathrm{X}$ \\
\hline & B & $x$ & $x$ & & $x$ & $x$ & & & $X$ & $\mathrm{x}$ & $\mathrm{X}$ & $\mathrm{X}$ & $\mathrm{X}$ \\
\hline & C & $x$ & $x$ & $\mathrm{X}$ & $X$ & $x$ & & & $x$ & $x$ & $x$ & $\mathrm{X}$ & $\mathrm{X}$ \\
\hline & $\mathrm{D}$ & $\mathrm{X}$ & $\mathrm{X}$ & & $X$ & $\mathrm{X}$ & & $\mathrm{X}$ & & $\mathrm{X}$ & $\mathrm{X}$ & $X$ & $X$ \\
\hline \multirow{4}{*}{ Isolator } & $\mathrm{E}$ & $X$ & $\mathrm{X}$ & $\mathrm{X}$ & $X$ & $X$ & $\mathrm{X}$ & $\mathrm{X}$ & & $X$ & $\mathrm{X}$ & $X$ & $X$ \\
\hline & $\mathrm{F}$ & $\mathrm{X}$ & $\mathrm{X}$ & & $\mathrm{X}$ & $\mathrm{X}$ & $x$ & & $\mathrm{X}$ & $\mathrm{X}$ & $x$ & $\mathrm{X}$ & $\mathrm{X}$ \\
\hline & G & $\mathrm{X}$ & $\mathrm{X}$ & $\mathrm{X}$ & $\mathrm{X}$ & $\mathrm{X}$ & $\mathrm{X}$ & & $x$ & $\mathrm{X}$ & $x$ & $\mathrm{X}$ & $x$ \\
\hline & $\mathrm{H}$ & $\mathrm{X}$ & $\mathrm{X}$ & & $\mathrm{X}$ & $\mathrm{X}$ & $\mathrm{X}$ & $\mathrm{X}$ & & $\mathrm{X}$ & $\mathrm{X}$ & $\mathrm{X}$ & $\mathrm{X}$ \\
\hline
\end{tabular}

Table 1. Product Variations with Corresponding Process Flows/Routings

Both rotator and isolator products start out at a machining process where their housings, base clamps, hubs, and endcaps are produced. These machined components are shipped to an outside anodizing process. Upon return, on an average of one week later, the base clamps and the endcaps are sent to an etching process where part numbers and other alignment inscriptions are applied. They join back up with the housing and hubs and proceed to a cleaning operation. Following cleaning, the job flows into assembly \#1 where a magnet, optical crystal, and endcaps are assembled and roughly installed into a base clamp. At this point an isolator and rotator of any particular size are identical. If the product is an isolator it flows into assembly \#2 where polarizing cubes are placed into the input and output hub. After 
assembly \#2, isolator path, and assembly \#1, rotator path, the optics move into either an oven cure, \#1, or an ultraviolet cure, \#2. From this point both products flow into assembly \#3 to have the hubs secured and assembly \#4 to have the endcaps secured. All products pass through a final alignment step for adjustment to customer specified settings followed by testing/verification of the entire unit. The base processes and flows of the system are visually depicted in Figure 4.

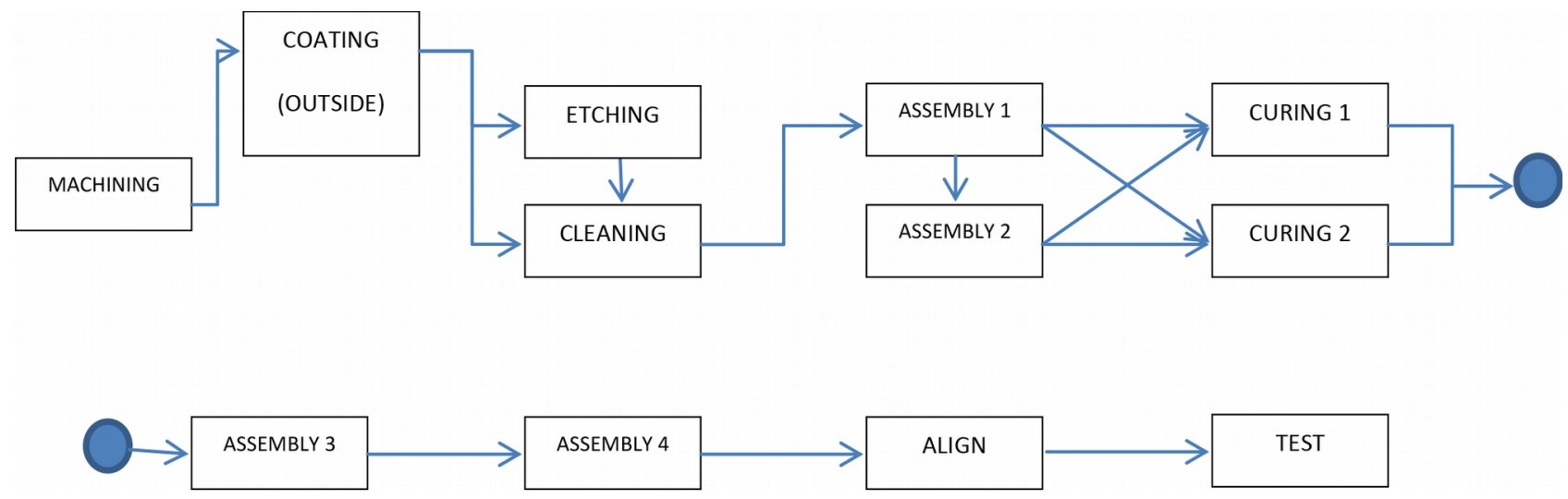

Figure 4. Base system processes and flows

Order arrival rate is defined as the frequency at which customer orders arrive. Time between arrivals, the reciprical of order arrival rate, ranges from once per month to once every six months. Cell capacity is defined as the number of jobs that each process can perform concurrently. Processing time is defined as the value added time the cell takes to transform the units/batches. Cell capacities and processing times are stated in Table 2.

\begin{tabular}{|l|c|c|r|}
\hline Process & Capacity & Average Processing Time & Average Processing Time (hours/pc) \\
\hline Machining & 4 & $18 \mathrm{~min} / \mathrm{pc}$ & 0.075 \\
\hline Coating (Outside) & 250 & 1 week $(1$ to $250 \mathrm{pcs})$ & 40.000 \\
\hline Etching & 1 & $2 \mathrm{~min} / \mathrm{pc}$ & 0.033 \\
\hline Cleaning & 500 & 8 hours $(1$ to $500 \mathrm{pcs})$ & 8.000 \\
\hline Assembly 1 & 1 & $10 \mathrm{~min} / \mathrm{pc}$ & 0.167 \\
\hline Assembly 2 & 1 & $6 \mathrm{~min} / \mathrm{pc}$ & 0.100 \\
\hline Curing 1 & 100 & $12 \mathrm{hours}(1 \mathrm{to} 100 \mathrm{pcs})$ & 12.000 \\
\hline Curing 2 & 6 & $4 \mathrm{~min}(1 \mathrm{to} 6 \mathrm{pcs})$ & 0.067 \\
\hline Assembly 3 & 1 & $3 \mathrm{~min} / \mathrm{pc}$ & 0.050 \\
\hline Assembly 4 & 1 & $3 \mathrm{~min} / \mathrm{pc}$ & 0.050 \\
\hline Align & 1 & $5 \mathrm{~min} / \mathrm{pc}$ & 0.083 \\
\hline Test & 1 & $5 \mathrm{~min} / \mathrm{pc}$ & 0.083 \\
\hline
\end{tabular}

Table 2. Cell Capacities and Processing Times 
Applying Little's Law from Hopp and Spearman (2011)

$$
\text { WIP }=\text { Cycle Time }(\mathrm{CT}) * \text { Throughput }(\mathrm{TH})
$$

the minimum lower bound for the WIP can be determined. Having too little WIP can starve processes, causing interruptions in production flow and lead to long lead times (Standridge, 2013). The cycle time (CT) for each product type is calculated with a summation of the process flow steps in Table 1 with the processing times and capacities in Table 2 and using the average order size, 8. The throughput (TH) for each product type is derived from the average annual order totals from the last three years. Using a summation of Little's Law for each of the eight different product types and flows yields a lower bound WIP level of 25 batches. This is shown in detail in Table 3.

\begin{tabular}{|l|c|c|r|r|r|}
\hline \multirow{2}{*}{ Product } & $\begin{array}{c}\text { Variation } \\
\text { (Flow) }\end{array}$ & $\begin{array}{c}\text { CT } \\
\text { (hrs / batch) }\end{array}$ & $\begin{array}{c}\text { Avg. Annual Volume } \\
\text { (8 piece order) }\end{array}$ & $\begin{array}{c}\text { TH } \\
\text { (order/hrs) }\end{array}$ & $\begin{array}{c}\text { WIP }=\text { (CT * TH) } \\
\text { (batches) }\end{array}$ \\
\hline \multirow{4}{*}{ Rotator } & $\mathrm{A}$ & 23.728 & 532.793 & 0.266 & 6.321 \\
\cline { 2 - 7 } & $\mathrm{B}$ & 11.553 & 59.063 & 0.030 & 0.341 \\
\cline { 2 - 7 } & $\mathrm{C}$ & 11.817 & 667.284 & 0.334 & 3.943 \\
\cline { 2 - 7 } & $\mathrm{D}$ & 23.464 & 108.704 & 0.054 & 1.275 \\
\hline \multirow{3}{*}{ solator } & $\mathrm{E}$ & 24.528 & 414.923 & 0.207 & 5.089 \\
\cline { 2 - 7 } & $\mathrm{F}$ & 12.353 & 141.375 & 0.071 & 0.873 \\
\cline { 2 - 7 } & $\mathrm{G}$ & 12.617 & 310.650 & 0.155 & 1.960 \\
\cline { 2 - 7 } & $\mathrm{H}$ & 24.264 & 352.079 & 0.176 & 4.271 \\
\hline
\end{tabular}

Table 3. Minimum WIP Level Calculations

The stations included in the CONWIP control loop are shown with a dashed box in Figure 5. The machining and outside processing (coating) will not be included in the control loop as a product cannot be controlled once it leaves the manufacturing site. Therefore, the CONWIP loop will include all processes post-Coating through Test. The POLCA cells are shown as solid ovals. Thus, the POLCA system will comprise of three loops: (1) Etch/Clean $\rightarrow$ Assembly 1_2, (2) Assembly 1_2 $\rightarrow$ Cure 1_2, (3) Cure 1_2 $\rightarrow$ Assembly 3_4 Align Test. 


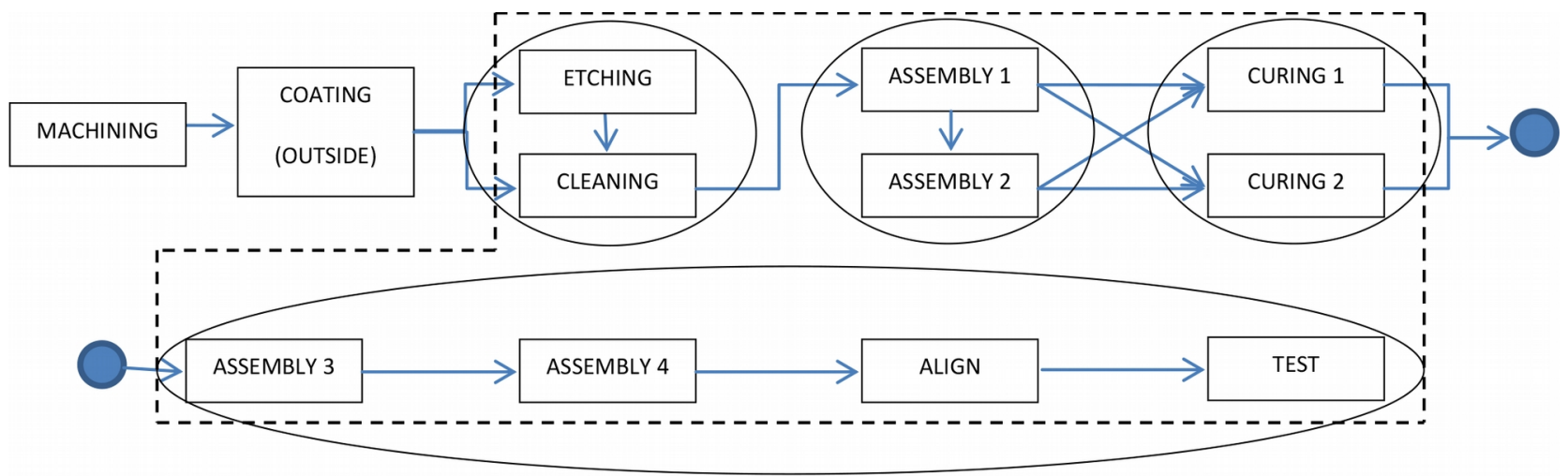

Figure 5. CONWIP and POLCA system loops

The sources of variation are the number of orders for each product per year, the number of number of pieces in each order, the manual operating times, and the number of pieces of in each batch operation: shipped to the coating process and processed in the cleaning and curring processes. The latter disrupts flow but can be controlled as a manufacturing operating parameter. For this study, the target number of pieces per batch operation was set to 100 for coating, cleaning, and cure 1 such that the first order that caused the batch to exceed 100 triggers the start of the operation. Cure 2 was allowed to work on one piece at a time. Note also that cleaning and curing 1 are automated processes with long processing times which can be modeled as constants.

\section{Simulation Modeling and Experimentation}

The goal of the simulation study is to find the minimal WIP level at which a short lead time can be achieved. This can be accomplished by increasing the number of CONWIP and POLCA signal cards starting at the minimum WIP of 25. Note that the number of POLCA cards will exceed the maximum observed WIP as the control areas for individual POLCA card types overlap. Two sets of experiments will be conducted. In the constant case, the order arrival rate, the number of pieces in order (order size with average of 8), and the operation times are treated as constants. In the random case, the number of orders is modeled as Poisson distributed, the order size as uniformly distributed between 1 and 15 pieces, and the operation times as uniformly distributed between $80 \%$ and $120 \%$ of the average. This approach is consistent with the discuss in Hopp and Spearman (2011) concerning a reasonable range of variability for production systems.

The order size range of 1-15 pieces is consistent with a low volume manufacturing environment. Each batch will be processed through the entire system as one job to help ensure consistency of processing. While a batch may consist of multiple pieces, only one CONWIP and/or POLCA signal card will 
accompany the batch. This approach automatically accommodates the order quantity and is an advantage of a load-based POLCA (LB-POLCA) system (Vandaele, Nieuwenhuyse, Claerhout \& Cremmery, 2008).

All orders are processed on an earliest calendar due date basis and treated as though there is not any finished goods inventory from which to fulfill them. The simulation model will ignore the effects of quality rejected materials, scrap, downtime, and WIP rework, which are all minimal.

Simulation run time is 240 production days, one year. This is reasonable considering that the longest time between arrivals for this family of products is typically no longer than six months.

Table 4 summarizes the simulation design of experiments.

\begin{tabular}{|l|l|}
\hline Element of the Experiment & Values for a Particular Experiment \\
\hline Model Parameters and Their Values & $\begin{array}{l}\text { WIP level expressed as either the CONWIP parameter or the } \\
\text { number of POLCA cards }\end{array}$ \\
\hline Performance Measures & Lead Time; Maximum WIP Level; Throughput \\
\hline Random Number Streams & $\begin{array}{l}\text { Number of arrivals of each of the eight part types per day } \\
\text { when Posson distributed; order size; manual operation times }\end{array}$ \\
\hline Initial Conditions & Empty and idle \\
\hline Number of Replicates & 1 for constant case; 20 for random case \\
\hline Simulation End Time / Event & 1 year (240 days) \\
\hline
\end{tabular}

Table 4. Simulation Experimental Design

\subsection{Verification and Validation}

Next model verification and validation are discussed. The techniques used are those discussed in Sargent (2012) specifically tracing entities through all processes as well as the use of simple analytic models such as balance equations and utilization computations. Law (2007) also indentifies tracing entities as a specific verification technique as well as using machine utilization for validation by comparing simulation results to data collected from the actual system.

Verification is done by balancing the number of arrivals with the number of departures plus the number remaining in the simulation at the end of the run. In the CONWIP model with constant arrivals, the number of entering orders, 2,587 was equal to the number of departing orders + the number of orders in process when the run was completed: $2,498+66$ with the CONWIP parameter set to a very large number. Identical results were yielded for the POLCA model with constant arrivals and the number of POLCA cards set to a very large number. 
Process flow for each load type was confirmed by tracing all the processes listed in sequence for both the CONWIP and POLCA models with constant arrivals. Typical results are shown in Table 5 which shows that "Load 97" follows the correct route.

Validation evidence was obtain by comparing the utilization of resources obtained by simulation with utilizations calculated from system data. A simulation of the exising system without the effect of CONWIP or POLCA controls is accomplished by setting the WIP level parameters to a very high number. Simulation experiments were conducted for both the constant and random cases. The results are shown in Tables 6 and 7. All absolute differences no more than $5 \%$ of the values calculated from system data except for the clean and cure1 stations for which the absolute difference is about $10 \%-11 \%$. Thus, validation evidence is considered to be obtained. Note that many of the operation utilizations are relatively low, less than $50 \%$.

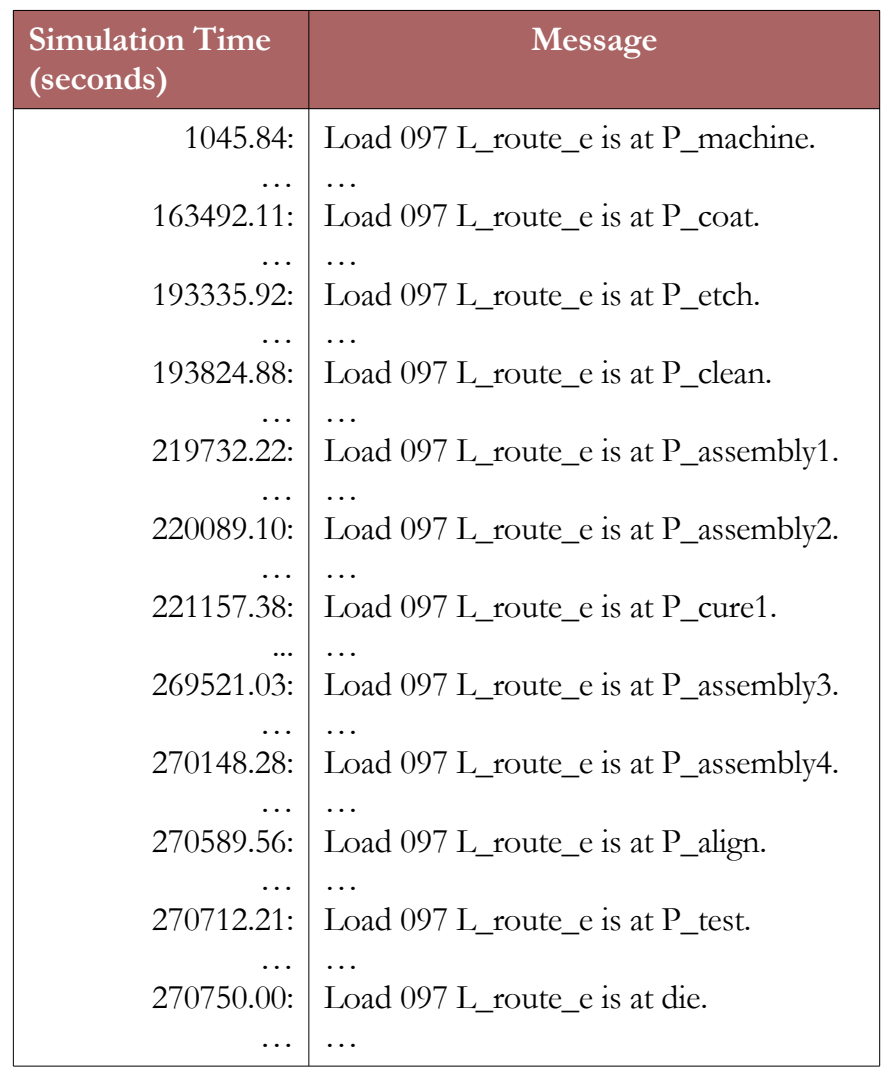

Table 5. Load Type Process Flow Tracing 


\begin{tabular}{|l|r|r|r|r|r|}
\hline Station & Calculated & Constant Case & Difference & Random Case & \multicolumn{1}{c|}{ Difference } \\
\hline Machine & $40.42 \%$ & $40.50 \%$ & $0.08 \%$ & $40.58 \%$ & $0.16 \%$ \\
\hline Etch & $13.24 \%$ & $13.50 \%$ & $0.26 \%$ & $12.98 \%$ & $0.27 \%$ \\
\hline Clean & $44.91 \%$ & $40.50 \%$ & $4.41 \%$ & $40.20 \%$ & $4.71 \%$ \\
\hline Assembly1 & $90.00 \%$ & $87.00 \%$ & $3.00 \%$ & $86.78 \%$ & $3.23 \%$ \\
\hline Assembly2 & $25.40 \%$ & $24.00 \%$ & $1.40 \%$ & $24.45 \%$ & $0.95 \%$ \\
\hline Cure1 & $24.45 \%$ & $22.00 \%$ & $2.45 \%$ & $21.65 \%$ & $2.80 \%$ \\
\hline Cure2 & $16.45 \%$ & $16.50 \%$ & $0.05 \%$ & $15.83 \%$ & $0.63 \%$ \\
\hline Assembly3 & $26.95 \%$ & $25.50 \%$ & $1.45 \%$ & $25.95 \%$ & $1.00 \%$ \\
\hline Assembly4 & $26.95 \%$ & $25.50 \%$ & $1.45 \%$ & $25.95 \%$ & $1.00 \%$ \\
\hline Align & $44.73 \%$ & $43.50 \%$ & $1.23 \%$ & $42.90 \%$ & $1.83 \%$ \\
\hline Test & $44.73 \%$ & $43.50 \%$ & $1.23 \%$ & $42.90 \%$ & $1.83 \%$ \\
\hline
\end{tabular}

Table 6. Individual Resource Utilization Comparison and Validation For CONWIP model

\begin{tabular}{|l|r|r|r|r|r|}
\hline Station & Calculated & Constant Case & Difference & Random Case & \multicolumn{1}{c|}{ Difference } \\
\hline Machine & $40.42 \%$ & $40.50 \%$ & $0.08 \%$ & $40.58 \%$ & $0.16 \%$ \\
\hline Etch & $13.24 \%$ & $13.50 \%$ & $0.26 \%$ & $12.98 \%$ & $0.27 \%$ \\
\hline Clean & $44.91 \%$ & $40.50 \%$ & $4.41 \%$ & $40.20 \%$ & $4.71 \%$ \\
\hline Assembly1 & $90.00 \%$ & $87.00 \%$ & $3.00 \%$ & $86.78 \%$ & $3.23 \%$ \\
\hline Assembly2 & $25.40 \%$ & $24.00 \%$ & $1.40 \%$ & $24.45 \%$ & $0.95 \%$ \\
\hline Cure1 & $24.45 \%$ & $22.00 \%$ & $2.45 \%$ & $21.65 \%$ & $2.80 \%$ \\
\hline Cure2 & $16.45 \%$ & $16.50 \%$ & $0.05 \%$ & $15.83 \%$ & $0.63 \%$ \\
\hline Assembly3 & $26.95 \%$ & $25.50 \%$ & $1.45 \%$ & $25.95 \%$ & $1.00 \%$ \\
\hline Assembly4 & $26.95 \%$ & $25.50 \%$ & $1.45 \%$ & $25.95 \%$ & $1.00 \%$ \\
\hline Align & $44.73 \%$ & $43.50 \%$ & $1.23 \%$ & $42.90 \%$ & $1.83 \%$ \\
\hline Test & $44.73 \%$ & $43.50 \%$ & $1.23 \%$ & $42.90 \%$ & $1.83 \%$ \\
\hline
\end{tabular}

Table 7. Individual Resource Utilization Comparison and Validation For POLCA model

\section{Results and Comparisons}

Simulation results are presented for each WIP control system. Conclusions are drawn by comparing the results.

\subsection{CONWIP Results}

Results are shown in Table 8. First consider the results for the constant case. The number of orders processed becomes equivalent at a CONWIP parameter value of 32 to those processed when the work- 
in-process is unconstrained (a CONWIP parameter of infinite). The lead time continues to decrease as the CONWIP parameter value increases reaching only 3 hours more than for unconstrained WIP for a CONWIP parameter value of 33 and within 1 hour for a CONWIP parameter value of 34.

Now consider the results for the random case. The number of orders processed becomes equivalent at a CONWIP parameter value of 57 to those processed when the work-in-process is unconstrained with lead time also equivalent to that achieved when the work-in-process in not constrained.

\begin{tabular}{|c|c|c|c|c|c|c|}
\hline \multirow{3}{*}{$\begin{array}{l}\text { CONWIP } \\
\text { Control }\end{array}$} & \multicolumn{2}{|c|}{ Constant } & \multicolumn{4}{|c|}{ Random } \\
\hline & \multirow{2}{*}{$\begin{array}{l}\text { Completed } \\
\text { Orders }\end{array}$} & \multirow{2}{*}{$\begin{array}{l}\text { Average } \\
\text { Lead Time } \\
\quad(\mathrm{hr})\end{array}$} & \multirow{2}{*}{$\begin{array}{l}\text { Average } \\
\text { Completed } \\
\text { Orders }\end{array}$} & \multirow{2}{*}{$\begin{array}{l}\text { Average Lead } \\
\text { Time (hr) }\end{array}$} & \multicolumn{2}{|c|}{$\begin{array}{l}\text { 95\% Confidence Interval } \\
\text { for Mean Lead Time } \\
\text { (hr) }\end{array}$} \\
\hline & & & & & $\begin{array}{l}\text { Lower } \\
\text { Bound }\end{array}$ & $\begin{array}{l}\text { Upper } \\
\text { Bound }\end{array}$ \\
\hline 25 & 1,846 & 902 & 65 & 209 & 192 & 227 \\
\hline 30 & 2,326 & 379 & 117 & 213 & 200 & 227 \\
\hline 31 & 2,438 & 259 & 118 & 211 & 198 & 223 \\
\hline 32 & 2,493 & 206 & 132 & 211 & 199 & 224 \\
\hline 33 & 2,494 & 201 & 208 & 226 & 208 & 243 \\
\hline 34 & 2,495 & 199 & 234 & 221 & 205 & 237 \\
\hline 35 & 2,495 & 198 & 380 & 227 & 203 & 250 \\
\hline 40 & 2,494 & 198 & 864 & 238 & 222 & 254 \\
\hline 45 & 2,494 & 198 & 1,556 & 230 & 221 & 239 \\
\hline 50 & 2,494 & 198 & 2,059 & 228 & 220 & 236 \\
\hline 55 & 2,494 & 198 & 2,410 & 229 & 222 & 236 \\
\hline 56 & 2,494 & 198 & 2,334 & 228 & 221 & 235 \\
\hline 57 & 2,494 & 198 & 2,463 & 228 & 221 & 235 \\
\hline 58 & 2,494 & 198 & 2,471 & 229 & 222 & 236 \\
\hline 59 & 2,494 & 198 & 2,471 & 229 & 222 & 236 \\
\hline 60 & 2,494 & 198 & 2,470 & 229 & 222 & 236 \\
\hline (Infinite) & 2,495 & 198 & 2,470 & 229 & 218 & 240 \\
\hline
\end{tabular}

Table 8. CONWIP Parameter Control Simulation Results

\subsection{POLCA Results}

Each POLCA loop contains a batch process, either clean or cure 1, that operates on at least 100 pieces. Thus, an average order size of 8 pieces implies an average of 13 orders per batch operation. Thus, the minimum number of POLCA cards per loop is 13. For the constant case, 2197 combinations of POLCA loop card numbers were simulated, all combinations in the range 13 to 25 for each card. Table 
9 shows the combinations yielding the shortest lead time for each maximum WIP level from 27 through 40. Recall that the maximum WIP level is less than the number of POLCA cards due to the overlapping loops.

The throughput becomes equivalent to the unconstrained WIP case (infinite) shown in Table 8 for a maximum WIP value of 36. Lead time continues to decrease through a maximum WIP of 39.

\begin{tabular}{|c|c|c|c|c|c|c|}
\hline \multicolumn{4}{|c|}{ POLCA Control Loops } & \multirow{2}{*}{$\begin{array}{c}\text { Completed } \\
\text { Orders }\end{array}$} & \multirow{2}{*}{$\begin{array}{l}\text { Average Lead Time } \\
\text { (hr) }\end{array}$} & \multirow{2}{*}{$\begin{array}{l}\text { Maximum } \\
\text { WIP }\end{array}$} \\
\hline 1 & 2 & 3 & Total & & & \\
\hline 13 & 13 & 14 & 40 & 1,579 & 1,241 & 27 \\
\hline 13 & 14 & 14 & 41 & 1,677 & 1,125 & 28 \\
\hline 14 & 14 & 15 & 43 & 1,772 & 1,012 & 29 \\
\hline 15 & 14 & 14 & 43 & 1,867 & 882 & 30 \\
\hline 16 & 14 & 14 & 44 & 1,965 & 794 & 31 \\
\hline 16 & 15 & 15 & 46 & 2,065 & 660 & 32 \\
\hline 17 & 15 & 15 & 47 & 2,182 & 535 & 33 \\
\hline 18 & 15 & 15 & 48 & 2,327 & 380 & 34 \\
\hline 19 & 15 & 15 & 49 & 2,474 & 221 & 35 \\
\hline 20 & 15 & 15 & 50 & 2,490 & 212 & 36 \\
\hline 20 & 16 & 15 & 51 & 2,493 & 204 & 37 \\
\hline 20 & 17 & 16 & 53 & 2,495 & 200 & 38 \\
\hline 20 & 18 & 16 & 54 & 2,495 & 199 & 39 \\
\hline 20 & 19 & 16 & 55 & 2,495 & 199 & 40 \\
\hline
\end{tabular}

Table 9. POLCA Parameter Control Simulation Results - Constant Case

Now consider the results for the random case. The average number of loads processed first exceeds those processed when the work-in-process is unconstrained at an average maximum WIP of 73 and a total number of POLCA cards of 128. Lead time becomes equivalent to that of the unconstrained case for a maximum WIP of 68 and total number of POLCA cards of 122. 


\begin{tabular}{|c|c|c|c|c|c|c|c|c|}
\hline \multicolumn{4}{|c|}{ POLCA Control Loops } & \multirow{2}{*}{$\begin{array}{l}\text { Completed } \\
\text { Orders }\end{array}$} & \multirow{2}{*}{$\begin{array}{l}\text { Average Lead } \\
\text { Time } \\
\text { (hr) }\end{array}$} & \multicolumn{2}{|c|}{$\begin{array}{l}95 \% \text { Confidence Interval } \\
\text { for Mean Lead Time } \\
\text { (hr) }\end{array}$} & \multirow[t]{2}{*}{ Max WIP } \\
\hline 1 & 2 & 3 & Total & & & $\begin{array}{l}\text { Lower } \\
\text { Bound }\end{array}$ & $\begin{array}{l}\text { Upper } \\
\text { Bound }\end{array}$ & \\
\hline 35 & 26 & 27 & 88 & 969 & 213 & 189 & 238 & 60 \\
\hline 35 & 28 & 29 & 92 & 1,239 & 214 & 189 & 238 & 61 \\
\hline 35 & 29 & 29 & 93 & 1,420 & 215 & 190 & 239 & 62 \\
\hline 35 & 30 & 28 & 93 & 1,175 & 213 & 189 & 238 & 63 \\
\hline 40 & 41 & 41 & 122 & 2,056 & 229 & 222 & 237 & 68 \\
\hline 41 & 43 & 40 & 124 & 2,086 & 230 & 223 & 238 & 69 \\
\hline 41 & 42 & 43 & 126 & 2,063 & 229 & 222 & 236 & 70 \\
\hline 43 & 41 & 45 & 129 & 2,371 & 229 & 222 & 235 & 71 \\
\hline 43 & 41 & 40 & 124 & 2,462 & 230 & 223 & 236 & 72 \\
\hline 43 & 44 & 41 & 128 & 2,481 & 230 & 222 & 239 & 73 \\
\hline 45 & 40 & 40 & 125 & 2,504 & 230 & 223 & 238 & 74 \\
\hline 45 & 41 & 40 & 126 & 2,505 & 230 & 223 & 238 & 75 \\
\hline
\end{tabular}

Table 10. POLCA Control Simulation Results - Random Case

\subsection{Comparison}

The following can be concluded from the simulation results shown in Tables 8, 9, and 10. The results are consistent with those reported by Germs and Riezebos (2010).

First consider the constant case. As seen in Table 8, a CONWIP control level of 32 results in a number of completed orders equivalent to an infinite WIP control level that is no WIP control. As seen in Table 9, an equivalent number of completed orders is achieved for a control level of 50 total POLCA cards and a maximum WIP of 36. The lead times for the two control strategies are equivalent for the above control levels. There is no random variation. Thus, it can be concluded that the higher number of POLCA cards and maximum WIP versus CONWIP to achieve an equivalent number of completed orders (throughput) has do with the differences in order flow caused by the two control strategies. With CONWIP, there is no constraint of order flow from station to station. With POLCA, a card must be obtained to enter each loop which constrains order flow. For this system, the constrained flow requires a high level of maximum WIP to achieve the same throughput with the same lead time. On the other hand for some systems, POLCA can present orders from collecting in one part of the system only and blocking flow, while CONWIP cannot. It appears that CONWIP performs better for this case due to batch operations and the relatively low utilization of the manual operations.

Next consider the random case. There are three sources of variation: number of orders, number of pieces per order, and manual operation times. The variation in the latter is smaller that the other two and likely 
has little impact. The squared coefficient of variation associated with the number of orders is one by definition of the Poisson distribution. The squared coefficient of variation of the manual processing times is 0.013 , two orders of magnitude less. With order sizes ranging from 1 to 15 pieces, the number of order per batch for cleaning and curing operations is highly variable as well. Hopp and Spearman (2011) discuss how lead time is proportional to the squared coefficient of variations of the number of orders and of processing times.

Thus, it is not surprising that the CONWIP level needed to achieve an equivalent number of completed orders to those achieved with no WIP control rises from 32 in the constant case to 57 in the random case as shown in Table 8 . Lead time rises by about $10 \%$ with a narrow $95 \%$ confidence interval for the true mean lead time, a half-width of $3 \%-4 \%$ of the average.

In the same way, the POLCA cards needed to achieve an equivalent number of completed orders to those achieved with no WIP control more than doubles from 50 in the constant case to 128 in the random case with the average maximum WIP doubling from 36 to 73 as seen in Tables 9 and 10. The average lead time is about the same as for the CONWIP case and also has a narrow confidence interval half-width.

\section{Summary}

In summary, this case study focused on two strategies, CONWIP and POLCA, for controlling WIP in a HMLV, photonics industry manufacturing environment with 12 products and batch operations using lead time, maximum WIP, and throughput as the primary performance measures. A discrete event simulation model and experiment were employed.

Based on the simulation results, it can be concluded that the CONWIP control performs better than the POLCA control for this system. The CONWIP control achieves maximum throughput at a lower maximum WIP level than POLCA for both the constant and random cases. The average lead times for CONWIP and POLCA for the maximum throughput level are equivalent in both the constant and random cases. Any issues with WIP gathering in one area of the system, which POLCA could prevent but CONWIP cannot, were not encountered in this system likely due to the batch operations and relatively low utilizations of the manual operations.

The constant case and the random case provide lower and upper bounds on the system performance. That is the random variation in the system is likely more than the constant case and likely less than the random case which is the practical worse case. Thus the need WIP level if CONWIP is used for example is in the range of 32 to 57. 


\section{References}

Duggan, K.J. (2002). Creating Mixed Model Value Streams: Practical Techniques for Building to Demand. New York, NY: Productivity Press.

Germs, R., \& Riezebos, J. (2010). Workload balancing capability of pull systems in MTO production. International Journal of Production Research, 48(8), 2345-2360. http://dx.doi.org/10.1080/00207540902814314

Godinho-Filho, M., \& Saes, E.V. (2013). From time based competition (TBC) to Quick Response Manufacturing (QRM): the evoluation of research aimed at lead time reduction. International Journal of Advanced Manufacturing Tecbnology, 64, 1177-1191. http://dx.doi.org/10.1007/s00170-012-4064-9

Hopp, W., \& Spearman, M. (2011). Factory Physics. 3rd ed. Waveland Press.

Kabadurmus, O. (2009). A comparative study of POLCA and generic CONWIP production control systems in erratic demand conditions. IIE Annual Conference.Proceedings. 1197-1202. Available at: http://search.proquest.com.ezproxy.gvsu.edu/docview/192457092?accountid $=39473$

Kishnamurthy, A., \& Suri, R. (2000). A New Approach for Analyzing Quening Models of Material Control Strategies in Manufacturing Systems. Center for Quick Response Manufacturing, University of Wisconsin-Madison, Madison, WI.

Law, A.M. (2007). Simulation Modeling \& Analysis. 4th ed. New York: McGraw-Hill.

Sakhardande, R. (2011). A performance comparison between kanban and CONWIP through simulation. IIE Annual Conference Proceedings. 1-8. Available at: http://search.proquest.com.ezproxy.gvsu.edu/docview/1190330695?accountid=39473

Sargent, R.G. (2012). Verification and validation of simulation models. Journal of Simulation, 7, 12-24. http://dx.doi.org/10.1057/jos.2012.20

Spearman, M.L., Woodruff, D.L., \& Hopp, W.J. (1990). CONWIP: A pull alternative to kanban. International Journal of Production Research, 28(5), 879-894. http://dx.doi.org/10.1080/00207549008942761

Sprovieri, J. (2004). Managing high-mix, low-volume assembly. Assembly Magazine, Available at: http://www.assemblymag.com/articles/83764-managing-high-mix-low-volume-assembly (accessed April 2016)

Standridge, C.R. (2013). Beyond Lean: Simulation in Practice. 2nd ed. Available at: http://scholarworks.gvsu.edu/books/6/ (Accessed: April 2013).

Suri, R. (2010) It's About Time: The Competitive Advantage of Quick Response Manufacturing. New York, NY: Productivity Press. http://dx.doi.org/10.1201/EBK1439805954 
Vandaele, N., Nieuwenhuyse, I.V., Claerhout, D., \& Cremmery, R. (2008). Load-Based POLCA: An Integrated Material Control System for Multiproduct, Multimachine Job Shops. INFORMS. Manufacturing \& Service Operations Management, 10(2), 181-197. http://dx.doi.org/10.1287/msom.1070.0174

Journal of Industrial Engineering and Management, 2016 (www.jiem.org)

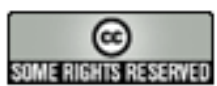

Article's contents are provided on an Attribution-Non Commercial 3.0 Creative commons license. Readers are allowed to copy, distribute and communicate article's contents, provided the author's and Journal of Industrial Engineering and Management's names are included. It must not be used for commercial purposes. To see the complete license contents, please visit http://creativecommons.org/licenses/by-nc/3.0/. 